THURSDAY, SEPTEMBER I3, I883

\section{SCIENTIFIC ASPECTS OF THE JAVA CATASTROPHE}

$C$ AUTION and scepticism, which are necessary to the student of every branch of natural science, ought to be the especial attributes of the vulcanologist and seismologist. No other natural phenomena so strikingly affect the imagination or so powerfully excite the fancy as do the volcanic outburst and the earthquake. These catastrophes usually occur too with such startling suddenness and with such an entire absence of warning that the witnesses are not unnaturally paralysed by fear and terror. Under such circumstances the wildest and most improbable stories are received and circulated with easy credence, and no attempt is made to separate the real from the imaginary.

Illustrations of these remarks might be adduced in connection with each of the great subterranean disturbances which have taken place during recent years. Thus the accounts received of the earthquake of Agram stated that fissures had opened in the ground from which smoke and flames issued and along which volcanic cones were thrown up. The report of the Commission appointed by the Hungarian Government to investigate the facts of the case upon the spot proves conclusively that these stories had no other foundation than the emission of small jets of water and the formation by them of sand-cones, a phenomenon frequently witnessed during earthquake shocks. An article in the last number of this journal upon the recent earthquake in Ischia shows that similar discrepancies exist between the first hastily-published accounts and the soberer testimony of careful observers.

In the case of the Java catastrophe, however, there appears to have been at least one attempt to hoax the newspaper-reading public by deliberately manufactured accounts of the event. A detailed statement purporting to come from an eye-witness, and telegraphed by way of America, was published in many of the daily papers. The circumstances recorded in this statement would have been startling indeed had they been true, but, as a writer in the Scotsman has already pointed out, the account bears too manifestly on its face abundant proofs of its want of genuineness.

Setting aside these fictitious accounts, and making every allowance for the exaggeration naturally resulting from terror, and the difficulty which under the circumstances of the case there must be of obtaining reliable information, sufficient remains to prove that the recent catastrophe resulted from one of the grandest and most destructive volcanic outbursts which have occurred in modern times.

The scene of this outburst was at what is at the present day probably the focus of the mostintense volcanic activity upon the face of the globe. The Island of Java contains no less than forty-six great volcanic mountains, nearly one half of which have been in activity during historical times. This chain of volcanoes is continued in the southern part of Sumatra. Since the colonisation of these islands several volcanic eruptions on the very grandest scale have taken place, at points not very distant

VOL. XXVIII.-NO. 724 from the scene of the recent catastrophe. In 1772 occurred the great eruption of Papandayang, when the whole upper part of the mountain was blown away, leaving a vast crater fifteen miles long by six miles broad. The quantity of material ejected during this eruption was so great that, according to Dr. Junghuhn, an area of seven miles radius around the mountain was in a single night covered with scoriæ and ashes to the depth of nearly fifty feet. Forty native villages were overwhelmed, and 3000 persons perished. In 1822 the neighbouring volcano of Galunggong was in eruption, and 114 villages were buried beneath the scoriæ and ashes, while the destruction of human life was so great that more than 4000 killed were recorded in the official reports.

According to the most reliable accounts received up to the present time, the recent outbreak would appear to have been far more fatal to human life than either of its predecessors, and the most potent agent of destruction in this, as in so many other cases, would seem to have been the great sea-wave produced by the earthquake-shock, rather than the showers of materials ejected from the volcanoes.

Divested of their marvellous accompaniments, and read by the light of modern vulcanologic science, the accounts already received of this great catastrophe seem to prove the occurrence of the following events :-First, the ejection of enormous quantities of fragmentary materials; secondly, the production of great changes in the form and outlines of the volcanic Island of Krakatoa; thirdly, the throwing up of a line of $n \in w$ volcanic cones on a fissure opened in the sea-bed between Java and Sumatra; and, fourthly, the occurrence of one or more earthquake shocks, giving rise to forced sea-waves of great destructiveness.

The quantity of materials ejected during these eruptions is proyed by two facts recorded in the accounts already published: firstly, the widespread and long-continued darkness, doubtless produced by the clouds of finely comminuted dust carried away from the volcano by the wind; and, secondly, by the vast mass of scoriæ which seems to have accumulated upon and floated over many portions of the surface of the surrounding seas.

Concerning the extent and nature of the changes of the features of Krakatoa we must await further and reliable evidence. As in the case of Papandayang, the destruction of the volcano was doubtless primarily due to the eruptive action, which truncated the cone and formed a gigantic crater, and whether or not this action was accompanied by subsidence, whereby the disappearance of the island was consummated, it remains for further investigations to determine. It is well, however, to bear in mind that many reputed cases of the submergence of islands have on further examination resolved themselves into the removal of materials by explosive action, just as most instances of the elevation of volcanic islands above the sea-level have been doubtless due to the piling up of the materials above the level of the waves.

The position and relations of the new line of volcanic cones must be determined by the surveying vessels which will doubtless be sent to the spot so soon as it is considered safe to do so. Fortunately a number of admirable charts of these seas have been constructed by the hydrographers of this and other countries, and by a comparison of these with the new charts which will now have to be 
made we shall be able to judge of the actual changes in the features of this part of the globe which have been wrought by this great outburst. It appears to have been the first belief of the naval authorities upon the spot that these changes were of such magnitude as to render it unsafe for vessels to attempt to pass the Straits of Sunda until new surveys had been made. Later accounts, however, prove that the principal channel by which vessels traverse the straits has remained unaffected by the eruptions.

We may confidently hope that a comparison of the times at which the great sea-wavc, produced by the earthquake, reached various ports will enable us to correct and extend our knowledge concerning the depth of certain portions of the Pacific and Indian Oceans. For this, as for many other details of great importance to science, we must await the careful collection and sifting of evidence which will doubtless be undertaken by a Commission appointed by the Dutch Government.

The portion of the Island of Java visited by this terrible calamity is exceedingly fertile, rich, and populous, and if the present estimate of the loss of life be not cxcessive, this catastrophe must probably rank as the greatest which has occurred in modern times, so far as the destruction of human life is concerned.

The repeated eruptions of Vesuvius and Etna have failed to drive away the vine-dressers from the fertile slopes of those mountains, and in the same way the forces of destruction which evidently lie dormant beneath Java only produce temporary interruptions in its story of plenty and prosperity. As it is now, so was it in past geological times. The districts of Hungary, Auvergne, and the Inner Hebrides, which in former geological periods were subjected to subterranean disturbances similar in character and violence to those which now affect Java, were, in the intervals between the volcanic outbursts, rich and fertile, a fact which is testified to by the remains of forests and of the wild animals which roamed through them, found in the deposits lying between successive lava-flows. Volcanic eruptions are frequently very destructive; carthquake shocks are often still more fatal to man and his works; but fortunately succcssive catastrophes of both kinds are usually separated by long intervals of time, and it is the recognition of this fact which leads men to brave alike both kinds of danger.

\section{AUTUMN SANITATION}

$\mathrm{I}^{\mathrm{T}}$ $\mathrm{T}$ is not only the steady decline of cholera in Egypt that gives substantial assurance that we shall now escape any epidemic in this country, but it is also the advancing season. There are, however, few subjects concerning which less is known than the influence of climate and season on the progress of the infectious diseases. But, as regards cholera, we know from experience that it is not very likely to make its appearance in this country when once the colder weather has set in. It has generally frst shown itself with us during the hot summer months, and it is probable that a foul, damp air, together with a certain degree of warmth, are most favourable to its prevalence. It is not that we have never suffered from it during the colder months, for it was somewhat widely prevalent in October and November of 1853 , the year which preceded the great epidemic of $x 854$, when so many cities, both in the Old and New World, were devastated. And even though actual winter has, even on such an occasion as that referred to, for a time completely checked the further progress of cholera, yet there is no reason to believe that any cold which the human frame can bear has the power of destroying the infection. At Moscow and at Orenburg in 1830 cholera prevailed in spite of a temperature of $-4^{\circ} \mathrm{F}$. And judging from analogy it would appear that much lower degrees of temperature than these fail to destroy infections such as that of cholera. Thus, tubes containing the characteristic spores of the bacillus anthracis have been exposed to a tcmperature of $-32^{\circ} \mathrm{F}$.; and yet on being thawed they have remained potent for harm as before. Indeed, we may infer that, provided other conditions necessary for the life of the contagion are present, warmth is not essential, and that no amount of cold is absolutcly incompatible with the development either of the cholera poison or of the infection of many other contagia. Still, cholera has bcen with us essentially a summer epidemic, and as each week of the present month passes away without its being imported into the country we may feel more and more assured that we have succeeded in escaping the danger of an outbreak.

There is also another disease that with the commencement of autumn rapidly subsides. We refer to that form of diarrhcea known as infantile, a specific disease that causes year by year a large fatality, especially in certain of our manufacturing towns. This disease, too, is, to a certain extent, one of season. At Leicester, Preston, and Nottingham, the death-rate from this cause is always exceptionally high during the third quarter of the year, its main incidence being on the first two months of the quarter. Thus, taking the year I881, it appears that, whereas the mortality from this cause in the twenty large towns and cities of England was 409 and 593 respectively, it rose to 4390 in the third quarter. But temperature alone does not account for this large mortality. Oldham, Rochdale, and Halifax resemble the three towns abovenamed in many important social and other respects; they do not materially differ from them as regards climate, and yet the infantile diarrhcea death-rate is with them always exceptionally low. Indeed the difficult problems connected with the etiology of this disease are such that the Government have commissioned Dr. Ed. Ballard to make a comprehensive inquiry into its causes, and it is hoped that his investigations, which have now been in progress for more than two years, will throw important light on the whole subject.

But as the diseases of one season subside those of another make their appearance. Many of the public are under the vague impression that cold weather and a good sharp frost have some effect in "clearing the air" and in getting rid of infection. But, as regards some diseases, this is altogether a mistake. Thus, typhus fever and small-pox, which are at their lowest ebb, or altogether disappear, during the hot summer months, tond to reappear as the autumn sets in, and they assume their greatest force at the depth of winter. But this again is probably not all due to seasonal causes. The cold with which these diseases are so specially related forces those who are poor and ill-clad to remain huddled together 